\title{
Characterization of Trueperella pyogenes isolated from caseous lymphadenitis lesions in Korean native goats
}

\author{
Md. Aftabuzzaman ${ }^{\dagger}$, Hector Espiritu ${ }^{\dagger}$, Seon-Ho Kim, Lovelia Mamuad, Su-Jeong Jin, Sang-Suk Lee, Yong-II Cho* \\ Department of Animal Science and Technology, Sunchon National University, Suncheon 57922, Korea
}

Received November 24, 2021

Accepted December 8, 2021

Corresponding author:

Yong-Il Cho

E-mail: ycho@scnu.ac.kr https://orcid.org/0000-0001-7756-3416

${ }^{\dagger}$ These first two authors contributed

equally to this work.

\begin{abstract}
The study characterized Trueperella pyogenes (T. pyogenes) from caseous lymphadenitis (CLA) in Korean native goats (KNG). CLA samples $(\mathrm{n}=191)$ were obtained from abattoir-slaughtered KNG. Pus were obtained and Corynebacterium pseudotuberculosis was detected by PCR using PLD gene. Three PLD-negative samples (1.57\%) from supramammary lymph node were subjected to bacterial culture. Isolates were identified using $16 \mathrm{~S}$ rRNA and biochemically characterized by APIZYM. Phylogenetic and biochemical analyses identified the isolates as $T$. pyogenes, and have shown separate clusters and varied enzyme reaction, suggesting genotypic and phenotypic diversity. This first report of T. pyogenes-induced CLA in KNG provided information for further investigations.
\end{abstract}

Key Words: Caseous lymphadenitis, Korean native black goat, Trueperella pyogenes

\section{INTRODUCTION}

Trueperella pyogenes (T. pyogenes) is a gram-positive, coryneform bacterium, ubiquitous in the environment, and commonly inhabits the skin and mucosa of the gastrointestinal, upper respiratory, and urogenital tracts of animals (Yassin et al, 2011). This Actinomycete has an opportunistic nature because it causes diverse clinical manifestations, particularly purulent or suppurative infections, ranging from abscesses, lymphadenitis, mastitis, pneumonia, and pyelonephritis, affecting a variety of livestock species including mainly cattle, pigs, goats and sheep (Winn Washington et al, 2006). The pathogenicity of this bacterium could be attributed to certain mechanisms such as the potent pyolisin which is the main virulence factor that promotes tissue damage; as well as mucosal adherence/colonization-associated proteins including neuraminidases, fimbriae, and collagen-binding proteins (Risseti et al, 2017).

In Korea, the Korean native black goat (KNG) is the only indigenous breed of goat, and its products has his- torically served for alternative medicine, such as broths and extracts, rather than for meat consumption (Son 1999). This is due to the high level of polyunsaturated fatty acids (PUFA), and low levels of saturated fat and cholesterol, as well as the preference to other livestock meat (Son 1999). Recently, the trend on the demand for healthy food lead to the global increase in goat meat consumption due to its distinct nutritional components, compared to other red meats (Mazhangara et al, 2019).

Suppurative infections leading to lesions and lymphadenitis are among the main causes of reduced productivity and product quality in livestock causing significant economic losses in the industry (Rzewuska et al, 2019). These infections are mainly caused by pyogenic bacteria such as Staphylococcus spp., Streptococcus spp., Corynebacterium spp., T. pyogenes, and Rhodococcus equi (Rzewuska et al, 2019). One of these infections that causes damage to livestock production particularly in the goat industry is caseous lymphadenitis (CLA). CLA is a chronic, contagious disease characterized by a formation of abscesses in the lymph nodes. It is considered as

Copyright (c) The Korean Society of Veterinary Service. 
the main suppurative infection that affects small ruminants, specially goats, worldwide (Al-Traif et al, 2017). The known primary agent of CLA is Corynebacterium pseudotuberculosis, a non-spore forming, intracellular pathogen that can survive in the environment for long periods (Al-Gaabary et al, 2009). This persistent characteristic of $C$. pseudotuberculosis is accounted for its high transmission rate to animals within the flock. However, there are few studies claiming that other bacteria, like T. pyogenes, could also induce CLA in goats (Stefanska et al, 2007). This study describes the characterization of $T$. pyogenes isolated from CLA lesions in KNG.

\section{MATERIALS AND METHODS}

A total of 191 CLA lesion samples were taken from goat carcasses slaughtered at an abattoir located at Jeonnam province, Korea. All carcasses were examined by a veterinary inspector for observation of occurrence of CLA lesions. The lymph nodes with surrounding tissue or purulent lesions were excised and were immediately transported to the laboratory where the caseous or purulent material was collected. DNA was extracted using Qiamp DNA mini kit (Qiagen, Germany) from the sample, and molecular detection of a 203-bp region of C. pseudotuberculosis phospholipase-D (PLD) gene was amplified by PCR to identify which samples were $C$. pseudotuberculosis positive/negative following a published method (Sá et al, 2013). Then, bacterial isolation was carried out on all the samples by streaking a loopful of caseous material/pus on blood agar supplemented with $5 \%$ defibrinated sheep blood, then subsequently incubated for $24 \sim 72 \mathrm{~h}$ at $37^{\circ} \mathrm{C}$.

Single colonies were isolated and purified using the same medium. After cultivation, a loopful of each isolate was used for DNA extraction and PLD was detected. Afterwards, PLD-negative samples were subjected to biochemical test using APIZYM (BioMerieux, France) to evaluate the enzyme activity of isolates following the manufacturer's protocol. Lastly, molecular identification were performed by amplification of the 16S rRNA gene. PCR products were submitted to Macrogen (Macrogen, Inc., Korea) for sequencing. Sequences were assembled and identified using the Basic Local Alignment Search Tool (BLAST). Phylogenetic analysis of isolates was done using Molecular Evolutionary Genetics Analysis version 7 (MEGA7) by Maximum Likelihood method.

\section{RESULTS AND DISCUSSION}

Among the 191 CLA lesions collected and assessed, three (1.57\%) samples were PLD-negative. The presentation of CLA lesions were all superficial in the supramammary lymph node, and these abscesses contains more fluid purulence (Fig. 1A), compared to PLD-positive samples which contains cheesy (more solid) caseous material. This corroborated with the bacterial isolates as PCR amplification of purified isolates from these CLA lesions were also PLD negative. The cultural characteristics: small, irregular smooth and whitish colonies (Fig. 1B); and microscopy of Gram's stained samples showed no difference among all isolates (Fig. 1C).

Caseous lymphadenitis could afflict significant economic damage in the goat industry. In Korea where intensive goat farming is increasing (Kim et al, 2019), very
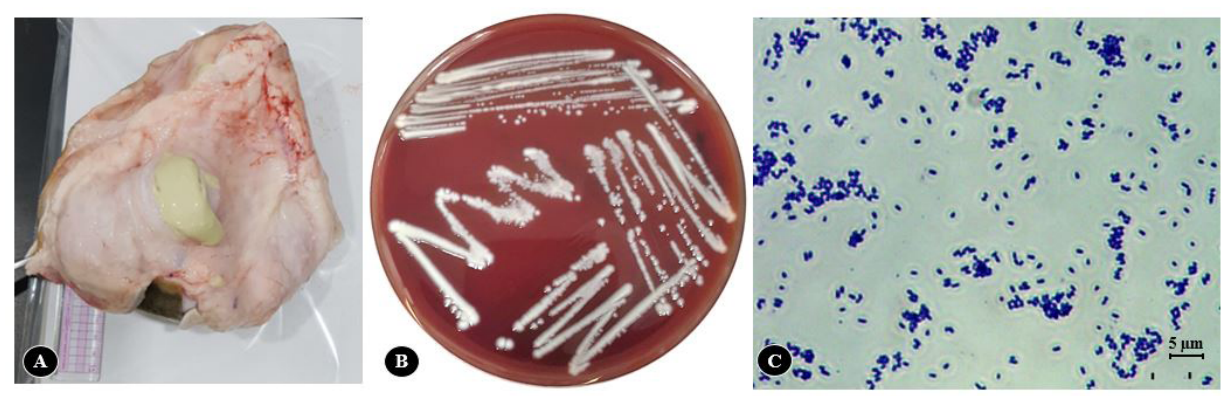

Fig. 1. CLA lesion excised from the supramammary lymph node with purulent material discharge (A). Plate purification of $T$. pyogenes showing the plate culture characteristics (B), and Gram's stained smear of T. pyogenes isolate showing Gram-positive pleomorphic or coccoid rods (C). 
few studies are currently available with regards to CLA. Previously, the relevance of $C$. pseudotuberculosis in KNG revealed that CLA is prevalent in the country, and calls for a proper strategy to control the disease (Jung et al, 2015). However, in case of T. pyogenes in CLA, no study in KNG is available. Here, we report the first isolation and characterization of $T$. pyogenes causing CLA in the indigenous breed of goat in Korea.

On the basis of cultural and differential staining, it is difficult to pinpoint the difference between $T$. pyogenes culture to C. pseudotuberculosis, therefore, more specific identification such as PCR should be considered. The result of this study also showed that only a low percentage of CLA occurrence is caused by T. pyogenes infection compared to those induced by C. pseudotuberculosis. In a previous retrospective study, the occurrence of $T$. pyogenes causing CLA was higher in goats in Brazil (Ribeiro et al, 2015) and in Spain (de la Fuente et al, 2017). T. pyogenes isolates originated from CLA lesions which formed in the supramammary lymph node. It was previously reported that $T$. pyogenes in intra- mammary gland is an important contributor in clinical mastitis in bovine (Alkasir et al, 2016). In goats, however, CLA in the supramammary lymph nodes was previously reported to also be mainly caused by $C$. pseudotuberculosis (C Schreuder et al, 2011). Even though KNGs are not bred for milk production, they can serve as reservoir of $T$. pyogenes which poses a potential threat in the biosecurity leading to future disease outbreaks, as well as zoonoses and antibiotic resistance. Furthermore, abscess disease which also proliferates in the lymph nodes is caused by Staphylococcus aureus subsp. anaerobius and mainly affects younger goats up to six months of age. A previous investigation in Spain reported that this bacteria, together with C. pseudotuberculosis and T. pyogenes could occur concomitantly causing CLA and abscess disease in goat and sheep herds (de la Fuente et al, 2017). Additionally, internal CLA caused by T. pyogenes also occurred in very small proportion in Polish sheep (2.00\%) (Didkowska et al, 2020).

The enzyme activity showed positive result for the alkaline phosphatase, esterase (C4), leucine arylamidase,

Table 1. Biochemical test of Trueperella pyogenes isolates using APIZYM compared to T. pyogenes and C. pseudotuberculosis type strains

\begin{tabular}{|c|c|c|c|c|}
\hline \multirow[b]{2}{*}{ No. } & \multirow[b]{2}{*}{ Enzyme assayed for } & \multicolumn{2}{|c|}{ T. pyogenes } & \multirow{2}{*}{$\begin{array}{c}\text { C. pseudotuberculosis } \\
\text { DSM20689 (Wink 2012) }\end{array}$} \\
\hline & & This study $(\mathrm{n}=3)$ & $\begin{array}{c}\text { Type strain } \\
\text { (Yassin et al, 2011) }\end{array}$ & \\
\hline 2 & Alkaline phosphatase & + & + & + \\
\hline 3 & Esterase $(\mathrm{C} 4)$ & + & + & + \\
\hline 4 & Esterase Lipase (C8) & - & + & + \\
\hline 5 & Lipase (C 14) & - & + & - \\
\hline 6 & Leucine arylamidase & + & - & - \\
\hline 7 & Valine arylamidase & - & + & - \\
\hline 8 & Cystine arylamidase & - & - & - \\
\hline 9 & Trypsin & - & - & - \\
\hline 10 & $\alpha$-chymotrypsin & - & - & - \\
\hline 11 & Acid phosphatase & + & - & + \\
\hline 12 & Naphthol-AS-B1-Phosphoarnidase & + & + & - \\
\hline 13 & $\alpha$-galactosidase & - & - & - \\
\hline 14 & $\beta$-galactosidase & + & - & - \\
\hline 15 & $\beta$-glucuronidase & + & + & - \\
\hline 16 & $\alpha$-glucosidase & + & + & + \\
\hline 17 & $\beta$-glucosidase & - & + & - \\
\hline 18 & $\mathrm{~N}$-acetyl- $\beta$-glucosaminidase & + & - & - \\
\hline 19 & $\alpha$-mannosidase & - & - & - \\
\hline 20 & $\alpha$-fucosidase & - & - & - \\
\hline
\end{tabular}

+ , positive reaction; -, negative reaction. 


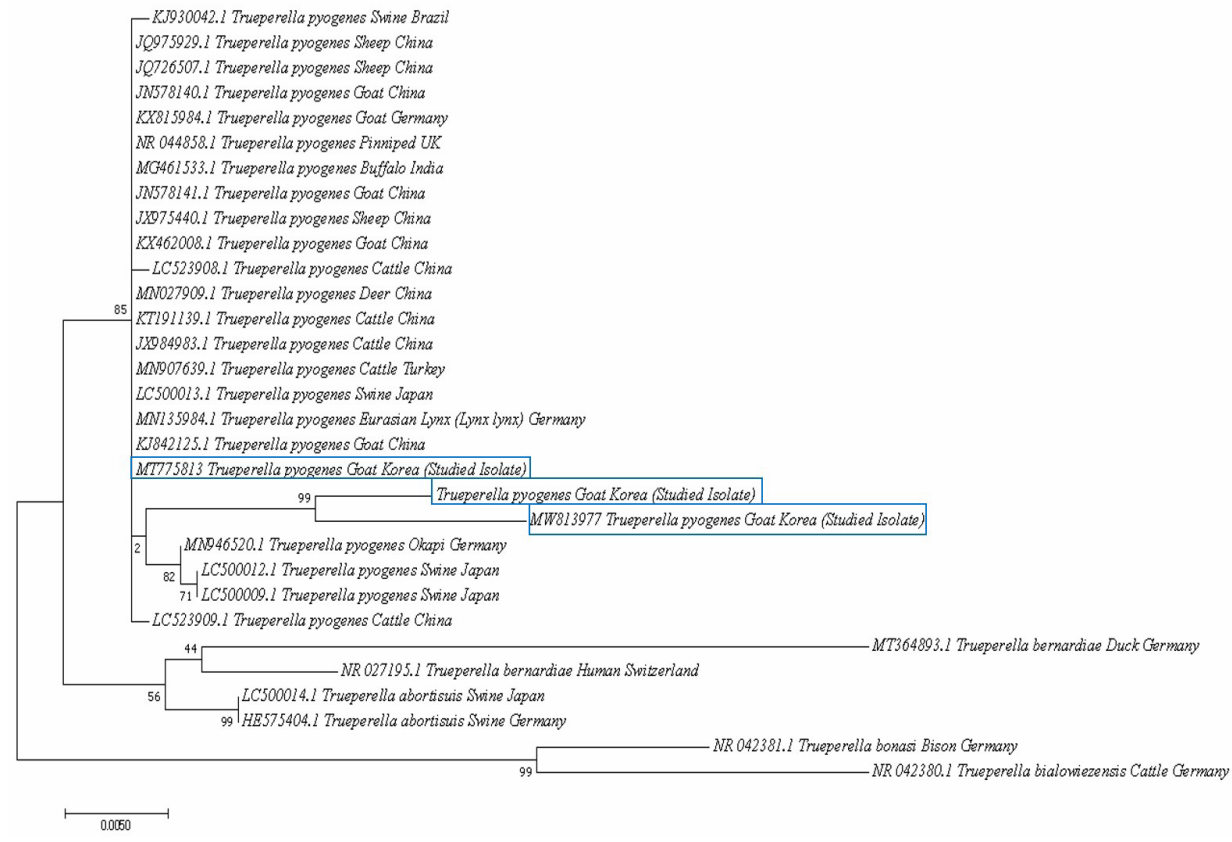

Fig. 2. Phylogenetic tree constructed using the maximum likelihood method based on 16S rRNA gene sequences $T$. pyogenes, and other Trueperella species. The tree was bootstrap resampled 1000 times. The bar represents 0.005 substitutions per nucleotide position. The analysis involved 25 nucleotide sequences T. pyogenes ( 3 from our study and 22 from the prior study), and six other Trueperella species retrieved from the GenBank ${ }^{\circledR}$ database. Evolutionary relationship was calculated using MEGA7. acid phosphatase, naphthol-AS-B1-phosphoarnidase, $\alpha$-glucosidase, $\beta$-galactosidase, $\beta$-glucuronidase, and $\mathrm{N}$-acetyl- $\beta$-glucosaminidase and negative for esterase lipase (C8), lipase (C14), cystine arylamidase, valine arylamidase, $\alpha$-galactosidase, $\alpha$-chymotrypsin, $\beta$-glucosidase, $\alpha$-fucosidase and $\alpha$-mannosidase. Compared to the type strain obtained from a previous characterization (Yassin et al, 2011), the enzyme activity of our isolates was different as presented in Table 1. The biochemical test result of $T$. pyogenes isolates showed variation in the enzyme reactivity compared to a previous study which suggests phenotypic diversity among strains (Yassin et al, 2011).

Molecular identification of the three PLD-negative isolates using the 16S rRNA gene revealed these samples as T. pyogenes, and the phylogenetic tree (Fig. 2) showed the evolutionary relationship to $T$. pyogenes from other country/host, and other members of genus Trueperella. One of the isolates closely grouped with the subclade containing most T. pyogenes isolates from diverse sources, but two of the isolates formed a distinct clade within the node containing all $T$. pyogenes. Additionally, the phylogenetic tree showed that two of our isolates may have further evolved from the other isolates. The phenotypic and genotypic diversity of $T$. pyogenes revealed in this study, as also observed previously, could provide essential information in the characterization of this bacterium to better understand its pathogenesis (Rogovskyy et al, 2018).

In conclusion, with the involvement of several bacteria in CLA, proper identification of which agent is involved is essential to lessen the risk of development of antimicrobial resistance among the pathogens present. Since this is the first reported cases of $T$. pyogenesinduced CLA in KNG, this study provided information that could be used for establishing diagnosis, treatment and control measures for CLA in the country. Currently, limited information is available with regards to $T$. pyogenes as a causative agent of CLA in goats. Further investigations should be conducted in order to deeply understand the pathogenic mechanisms, risk factors, and impacts of this bacterium in CLA.

\section{ACKNOWLEDGEMENTS}

The study was supported by a grant from the Cooperative Research Program for Agriculture Science and Technology Development (PJ014960032021) funded by 
the Rural Development Administration, Republic of Korea.

\section{CONFLICT OF INTEREST}

No potential conflict of interest relevant to this article was reported.

\section{ORCID}

Md. Aftabuzzaman, https://orcid.org/0000-0002-9436-8345 Hector Espiritu, https://orcid.org/0000-0001-9051-1995 Seon-Ho Kim, https://orcid.org/0000-0002-9350-1853 Lovelia Mamuad, https://orcid.org/0000-0002-1866-0897 Su-Jeong Jin, https://orcid.org/0000-0003-0224-2057 Sang-Suk Lee, https://orcid.org/0000-0003-1540-7041 Yong-Il Cho, https://orcid.org/0000-0001-7756-3416

\section{REFERENCES}

Al-Gaabary MH, Osman SA, Oreiby AF. 2009. Caseous lymphadenitis in sheep and goats: Clinical, epidemiological and preventive studies. Small Rumin Res. 87: 116-121.

Alkasir R, Wang J, Gao J, Ali T, Zhang L, Szenci O, Bajcsy AC, Han B. 2016. Properties and antimicrobial susceptibility of Trueperella pyogenes isolated from bovine mastitis in China. Acta Vet Hung. 64(1): 1-12.

Al-Traif B, Housawi FMT, Salem MA, Al-Saktawi KA, Fadlelmula A. 2018. Small Ruminants Abscesses: Bacterial Etiology, Antibiogram and Haematological Study in the East of Saudi Arabia. Microbiol Res J Int. 22(4): 1-11.

C Schreuder BE, ter Laak EA, Griesen HW. 1986. An outbreak of caseous lymphadenitis in dairy goats: First report of the disease in the Netherlands. Vet. Q. 8: 61-67.

de la Fuente R, de las Heras M, Torrijos C, Diez de Tejada P, Pérez-Sancho M, Carrión FJ, Orden JA, Dominguez-Bernal G. 2017. Isolation frequency of bacteria causing lymphadenitis and abscesses in small ruminants in central Spain. Small Rumin Res. 154:5-8.

Didkowska A, Zmuda P, Kwiecien E, Rzewuska M, Klich D, Krajewska-Wedzina M, Witkowski L, Zychska M, Kaczmarkowska A, Orlowska B. Anusz K. 2020. Microbiological assessment of sheep lymph nodes with lymphadenitis found during post-mortem examination of slaughtered sheep: implications for veterinary-sanitary meat control. Acta Vet Scand. $62: 1-7$.

Jung BY, Lee SH, Kim HY, Byun JW, Shin DH, Kim D, Kwak D. 2015. Serology and clinical relevance of Corynebacterium pseudotuberculosis in native Korean goats (Capra hircus coreanae). Trop Anim Health Prod. 47:657-661.

Kim HJ, Kim, HJ, Jang A. 2019. Nutritional and antioxidative properties of black goat meat cuts. Australasian J Anim Sci. 32(9): 1423-1429.

Mazhangara IR, Chivandi E, Mupangwa JF, Muchenje V. 2019. The Potential of Goat Meat in the Red Meat Industry. Sustain. 11(13): 3671.

Ribeiro MG, Risseti RM, Bolaños CA, Caffaro KA, de Morais AC, Lara GH, Zamprogna TO, Paes AC, Listoni FJ, Franco MM. 2015. Trueperella pyogenes multispecies infections in domestic animals: a retrospective study of 144 cases (2002 to 2012). Vet Q. 35(2):82-87.

Risseti RM, Zastempowska E, Twaruzek M, Lassa H, Pantoja JCF, de Vargas APC, Guerra ST, Bolaños CAD, de Paula CL, Alves AC, Colhado BS, Portilho FVR, Tasca C, Lara GHB, Ribeiro MG. 2017. Virulence markers associated with Trueperella pyogenes infections in livestock and companion animals. Lett Appl Microbiol. 65(2): 125-132.

Rogovskyy AS, Lawhon S, Kuczmanski K, Gillis DC., Wu J, Hurley H, Rogovska YV, Konganti K, Yang CY, Duncan K. 2018. Phenotypic and genotypic characteristics of Trueperella pyogenes isolated from ruminants. J Vet Diagnostic Investig. 30(3):348-353. Rzewuska M, Kwiecien E, Chrobak-Chmiel D, Kizer- 
wetter-Swida M, Stefanska I, Gierynska M. 2019. Pathogenicity and Virulence of Trueperella pyogenes: A Review. Int J Mol Sci. 20(11): 2737.

Sa M da CA de, Gouveia GV, Krewer C da C, Veschi JLA, Mattos-Guaraldi AL de, Costa MM da. 2013. Distribution of PLD and FagA, B, C and D genes in Corynebacterium pseudotuberculosis isolates from sheep and goats with caseus lymphadenitis. Genet Mol Biol. 36: 265-268.

Son YS. 1999. Production and uses of Korean Native Black Goat. Small Rumin Res. 34:303-308.

Stefanska I, Rzewuska M, Binek M. 2007. Corynebacterium pseudotuberculosis-infections in animals. Advances in Micriobiol. 46:101-112.

Wink J. 2012. Compendium of Actinobacte- ria. HZI-Helmholtz-Centre for Infection Research, Braunschweig. https://bacdive.dsmz.de/ strain/3113\#ref18770.

Winn Washington C, Allen SD, Janda WM, Koneman EW, Procop GW, Schreckenberger PC, Woods GL. 2006. Koneman's Color Atlas and Textbook of Diagnostic Microbiolgy. $6^{\text {th }}$ ed. Lippincott, Williams \& Wilkins.

Yassin AF, Hupfer H, Siering C, Schumann P. 2011. Comparative chemotaxonomic and phylogenetic studies on the genus Arcanobacterium Collins et al. 1982 emend. Lehnen et al. 2006: proposal for Trueperella gen. nov. and emended description of the genus Arcanobacterium. Int J Syst Evol Microbiol. 61:1265-1274. 